\title{
Geographical regularities in the distribution of the genes of cultivated plants
}

\author{
PRELIMINARY COMMUNICATION
}

\author{
N.I. Vavilov*
}

\begin{abstract}
Editorial Preface). Archives of Russian cytogenetics keep many-sided evidences of close interactions of chromosome studies with the fundamental genetics. Here we present one of the most exciting documents of the initial existence of such connection. It stressed, in particular, the strong practical motivation for development of wide botanical chromosomal studies under influence of global genetic approach built by Nikolai Vavilov. He was who brought together the famous national cytogeneticists in his institute in Leningrad (now again St. Petersburg), and it is demonstrated already in the first issue of the profile journal he inherited from former applied plant breeders. In 1927, a special number of the new-renamed "Bulletin of Applied Botany, of Genetics and Plant-Breeding" (former "Bulletin of Applied Botany and Plant-Breeding", 1927: vol. 17, No.3) has been dedicated "to the founder of genetical cytology in our country", Sergei G. Navashin. The volume included the papers under such names as G. Levitsky, I. Sveshnikova, H. Emme, M. Navashin, V. Rybin and G. Karpechenko and was completed by a small publication of N. Vavilov himself. This communication given as "preliminary" is important in many respects, drawing the far going idea for the genetic studies on the Linnean species (either in plants or among animals) and running right up to analyses of chromosome and genomic polymorphisms or polytypy activated far long ago after Vavilov's epoch.
\end{abstract}

Key words: fundamental genetics, gene geography, Linnean species, origin of cultivated plants, history of science.

\section{INTRODUCTION}

In studying the distribution of the botanical varieties of cultivated plants in the world and in trying to locate the focuses where the different cultivated plants have originated, the author has ascertained geographical centres embracing the diversity of phenotypes. A detailed study of the racial composition of the separate Linnean species has established systems of characters, corresponding to a certain degree to systems of genes, and the geographical regions of their concentration.

In the author's work "Studies on the Origin of Cultivated Plants" (Vavilov, 1926) the general results of these investigations are given.

Further investigations in regard to the cen-

* [Original: 1927. Bull. Appl. Bot. Genet. Plant-Breed. (Leningrad). 17(3): 411-419 (in Russian), 420-428 (in English]. 

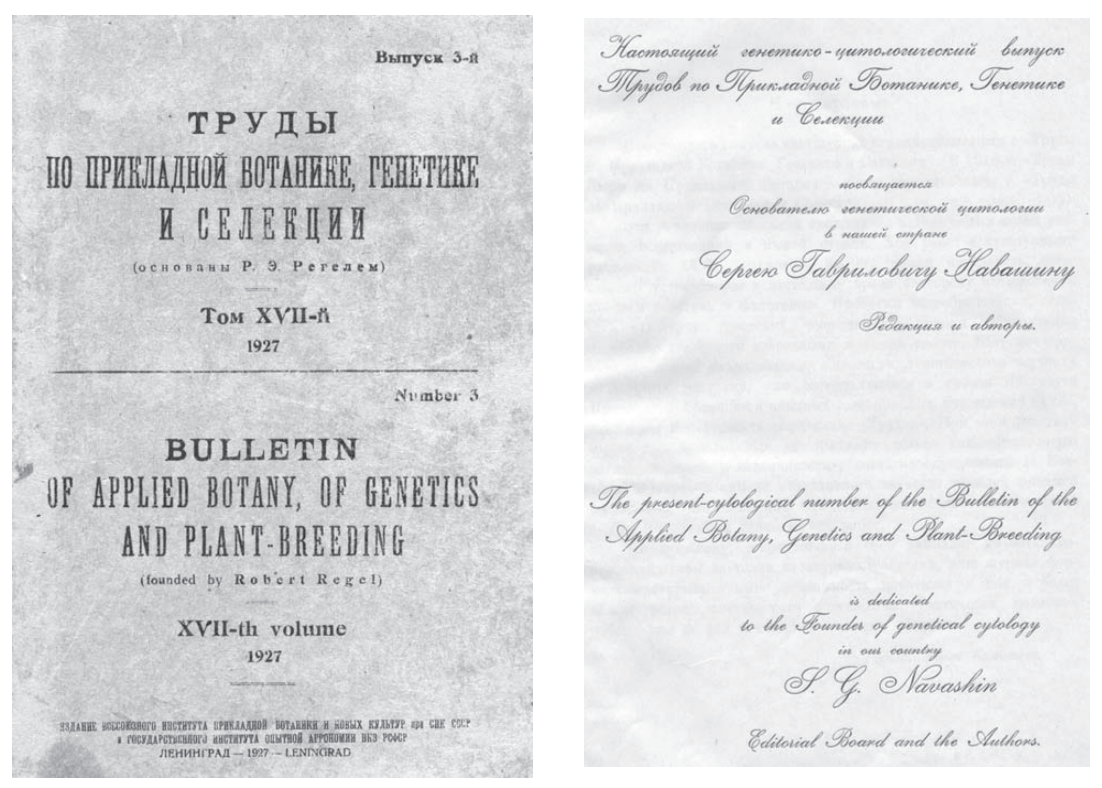

Fig. 1. A journal (1927) title with the dedication to S.G. Navashin.

tres of the origin of forms have revealed new facts and regularities.

\section{$\S 1$. CONCENTRATION OF DOMINANT FORMS. INCREASE OF THE NUMBER OF DOMINANT GENES TOWARDS THE CENTRES}

The direct study of the centres of the origin of cultivated plants, undertaken by expeditions of the Institute of Applied Botany (Leningrad) in the mountainous districts of Asia and Africa, in the countries bordering on the Mediterranean, and in Transcaucasia, has revealed not only a great diversity of forms but also a prevailing accumulation of dominant forms characterized by dominant gene in the centres. A considerable number of plants investigated us showed this regularity. Let us cite some instances.

(a) The most probable centre of the origin of cultivated rye, Secale cereale L., as well as of the whole genus Secale, are Eastern Asia Minor and Transcaucasia. In these countries are concentrated all species of rye, as well as the whole diversity of characters distinguishing the separate botanical varieties of rye. The most important fact is, however, that in these places not only a great number of forms have been found, but also many dominant forms, as red-eared, brown-eared, and even blackeared forms, as well as varieties with strongly marked pubescence. The colour of the ears and the pubescence of the glumes, observed in the weed rye of Asia Minor and Transcaucasia, distinguish this rye from the varieties of Europe, Afghanistan, Uzbekistan, Turkmenistan. Afghanistan and Tadjikistan (Mountainous Bokhara) competing numerically as regards the diversity of characters with Asia Minor and Transcaucasia, are chiefly characterized by recessive forms, as liguleless leaves, ${ }^{1)}$ yellow coloured ears, glabrous or slightly pubes-

${ }^{1)}$ The recessiveness of this character has been proved by studying the process of segregation of heterozygous forms. 
cent flowering glumes.

(b) Abyssinia is, according to our investigations, the centre where the cultivated varieties of the vast group of durum wheats, more exactly of the whole group of wheat species characterized by 28 chromosomes, have originated. Here the whole diversity of forms of hulled barley is concentrated, embracing a great number of endemic characters. But of still greater interest is the fact that in Abyssinia we meet with an abundance of dominant forms as nowhere else in the world.

Such are the black varieties of barley, varieties belonging to the group deficientes, which, as our experiments as well as those of other investigators have shown, are usually dominant in crosses with common European and Asiatic forms of $H$. vulgare, $H$. hexastichum and $H$. nutantes. In this country a great number of black-eared races, of forms with a strongly marked presence of anthocyan in plant and ear, about maturity are concentrated. Even the races of hull-less barley usually correlatively colourless, are here chiefly blackeared and with black grains.

As regards durum wheats, Abyssinia displays not only all varietal characters of Europe and Asia, as well as many original endemic forms, but many races with clearly dominant characters, unknown in Europe, are met with in this country. Such are the vast group of Abyssinian purple-grained wheats, the awnless forms of durum wheat, forms with coloured edges of the glumes; pubescent varieties are widely spread in this country. Experimental investigations of the nearest future are to ascertain in detail the genotypical composition of the forms of Abyssinia and Eritrea. But already at the present time the facts established by experiments with the few forms so far known to us, involuntarily draw our attention to the wide spread of dominant characters in Abyssinia. (c) Abyssinia is the principal centre of the Linnean species of wheat oats, Avena abyssinica, usually admixed to the sowings of emmer (Tr. dicoccum) and of barley. As far as we know, this species is peculiar to Abyssinia and the mountainous parts of Eritrea. The study of the varieties of these oats has revealed a great number of forms with dominant characters: pubescent, brown, gray glumes, etc.

(d) Abyssinia is probably the centre of origin of the forms of cultivated peas. The investigator is struck with the variety of forms exhibited by this plant and attention is involuntarily drawn by the presence of black-grained races unknown in Europe.

Among Cicer arietinum and Vicia faba, the former especially, black-grained races are often observed, which are perfectly unknown or of very rare occurrence in Turkestan and in the Caucasus.

(e) The region adjoining Northern India, South-Western Afghanistan, and the Southern parts of Mountainous Bokhara comprise the greatest diversity of species of soft wheat, club wheat, and round grained wheat (T. vulgare, T. compactum and T. sphaerococcum). In all probability it is in these regions that the principal centre where the whole group of soft wheats has originated must be sought. Here also we meet with a great number of forms showing dominant characters: compact type of ear, colour, pubescence of glumes, spikelets and glumes of the type inflatum.

(f) The potato exhibits in its varietal distribution a marked decrease of dominants towards the periphery of its area. Mexico, Peru, Chili, the incontestable primary centres of this crop, show numerous varieties with tubers and stolons of an intensive purple colour, with anthocyan spreading to the middle of the tubers. Crossing experiments show that this type of anthocyan colouring is strictly dominant.

(g) Mexico, as has been established by the 
expedition sent to this country by the Institute of Applied Botany, is one of the centres of indian corn. According to the observations of S.M. Bukassov, a decrease of dark coloured forms (as regards the colour of the cob) towards the Atlantic and Pacific coast manifests itself in this country.

(i) Lepidium sativum is comparatively widely spread in the Old World, but the chief diversity of its forms is concentrated in Eastern mountainous Africa, as our last expedition to Abyssinia and Eritrea had shown. Of essential importance is, that Abyssinia and Eritrea are characterized by the presence chiefly of dominant forms of Lepidium sativum (blackseeded, with dissected leaves etc.).

A number of similar instances could be given.

Summing up the above mentioned data, we come to the conclusion that the principal centres of the origin of forms, the focuses of diversity, which are of the highest importance for plant breeding, are characterized not only by a great number of forms but, which is of no less importance, by the presence of a great number of dominant forms.

The secondary centres of the origin of forms are, on the contrary, characterized by a diversity of chiefly recessive characters.

Many imported European garden crops, which have undergone prolonged selection, chiefly represent obvious recessives. By isolation, inbreeding a great number of new characters were obtained during the last years in corn: albinos of different types, liguliless races, many monstrosities. As a rule, these forms are recessive.

\section{§2. DOMINANT CHARACTERS IN ANIMALS AND MAN}

The investigation of the genesis of cultivated plants has led us to the conclusion that the principal centres of the origin of cultivated plants are connected to a considerable extent with the distribution of the principal seats of the primary human culture and to a certain degree with the centres of the diversity of domestic animals.

When travelling in Africa and Asia the author's attention was involuntarily attracted by the extraordinary diversity of races composing the cattle, goats and sheep in Abyssinia, Eritrea and South Western Afghanistan, the probable centres of origin of many cultivated plants. The artificial selection of form and colour is more marked in the domestic animals than in the plants, but their strikingly motley composition is still sufficiently persistent, and colours which according to the data of genetical investigations, so far it is possible to judge by appearance, are dominant, are very often widely spread.

This regularity is still more prominent in man. To the centres of origin of the principal crop plants of the Old World - rye, barley, wheat, beans, and flax - the predominance of dark coloured human races is peculiar. It is well known that, according to the data of hybridization, the character of black colour in the negroid races is determined by a series of dominant genes, a fact which in crosses with white people not infrequently leads to an apparently complete absorption of whiteness ${ }^{2}$.

In comparing the map of the principal centres of origin of the most important crop plants with that of the distribution of the co-

\footnotetext{
${ }^{2}$ It is interesting to note that even the ectoparasites of man show in Abyssinia the tendency of displaying dominant characters; the lice are represented in Abyssinia not only by their lighter coloured forms, but to a considerable degree also by black varieties.
} 
loured human races, prior to the migration of modern times, the general coincidence of the regions where the coloured races are concentrated with the primary centres of agriculture involuntarily claims notice.

\section{§3. General scheme of the VARIETAL GEOGRAPHICAL DISTRIBUTION OF CULTI-} VATED PLANTS, DOMESTIC ANIMALS AND OF MAN

The above stated explains to a certain degree the general scheme of the distribution of the varieties of cultivated plants, as well as of the races of domestic animals and races of man - a decrease of dominants from the centres towards the periphery of spreading.

The genetic bases of domestic animals, and of man itself, are in close connection with the genetic centres of cultivated plants, centres that at present time may be quite objectively located.

In its progress from the principal geographical genetical bases towards the periphery, the cultivated plant type becomes lighter in colour. Europe is chiefly characterized by white-eared rye, white-eared wheat, whiteeared barley; the coloured human races disappear. The Northern type seems as if the result of the failing out of the dominant genes. Proportionally to the spread of isolation, proceeds the accumulation of recessive forms. Thus arise recessive boreal types.

As if by physical dispersion, spreading through space, proceeded the division of the original dominant forms, the individualization of recessive forms. In one cases the isolation factors were islands, in others, deserts, and finally space itself. The recessive genotypes individualized in space, separating from the dominant types and propagating among themselves, gave rise to bodies of recessive races and varieties.
In studying the geography of the races of cultivated plants, we meet with instances illustrating the role played by geographical isolators in the separation of recessive types.

In the isolated high mountain districts of Badakshan, in Mountainous Bokhara, both representing ideal isolators, in one case owing to the Hindu-Kush which raises to a height of $5000 \mathrm{~m}$., in the other - to the Pamyr highlands, we have found liguleless rye and liguleless soft wheat. Both forms are distinctly recessive. In crosses with common races, as our experiments have shown, the characters of liguleness are conditioned at least by two genes.

In the island Cyprus, a series of liguleless varieties of durum wheat were discovered (Flaksberger, 1926). In this case it was the island that played the role of isolator. The principal centre of diversity of durum wheats is Abyssinia.

The oasis of Khiva is perfectly isolated in the North by the Aral Sea, in the South-West and in the east by the deserts Kara-Koum and Kizyl-Koum. In 1925 our expedition discovered in these places large bodies of whitegrained, white-flowering flax races which are of rare occurrence in the principal base of linseed, i.e., in the regions adjoining India.

In the Austrian mountains, the branches of the Pyrenees, we met with patches of whiteflowering wild flax - Linum angustifolium.

White-seeded recessive forms of Nicotiana rustica were found, according to the data of S.A. Eghize, in Middle Russia, a country far distant from the centre of origin of tobacco.

In separate cases, no doubt, the geographical isolation may have been conditioned by the artificial selection of recessive animal and plant races by man. In their essence, the process of geographical isolation and the influence of artificial selection are the same: from the genetical basis - the source of genes - the 
recessive forms were selected. The European as if emancipated himself from the prevalence of dominant genes. The schema is equally applicable to man, plant and animal. Thus were formed, in all probability, the recessive animal varieties of the Northern and Polar regions. Their genetic bases are inevitably situated in more Southern latitudes. The singling out of the above mentioned varieties was favoured by environment, natural selection, by the correspondence of the recessive colours to the external conditions. The dominant types might as well have reached the limits of distribution but, not being adapted to the environmental conditions, were eliminated. Thus, the progress of the geographical formation of the races may be referred in a considerable degree to the process of emancipation of the recessive genes.

The primary geographical centres embrace all genetical elements but owing to hybridization (especially in cross-pollinated plants and animals with their separate sexes) and the phenomenon of dominance, chiefly dominant types manifest themselves. We know at the present time that recessive types are readily emancipated by inbreeding - under conditions which include the coming of different genes.

The apparent diversity of some species, far away from their centres of origin, for instance in corn, may be explained by the singling out of homozygotes under the conditions of artificial isolation. Thus the explanation of the diversity of maize forms obtained by the plant breeder, is very simple.

From the fact that no recessive liguleless forms have been found in the principal centres, it does not follow that they do not exist potentially in genotypes of primary forms. This consideration explains many facts of the appearing deviations from the general scheme of centres.

\section{§4. Correction to the General SCHEME}

In regard to the most important cultivated plants we have established 5 principal geographical centres of origin (see "Studies on the Origin of Cultivated Plants"):

I. South Western Asia.

II. The mountainous part of China.

III. The mountainous regions of the Mediterranean Coast.

IV. The mountainous East Africa (Abyssinia and Eritrea).

V. The mountain regions of the New World (Mexico, Guatemala, Peru, Columbia).

To these principal centres, secondary ones, as for instance the Asiatic island centre (Japan, Java, Sumatra etc.) must be added.

In analyzing the process of the spreading of forms over the earth, the polyphyletism of the origin of many cultivated plants must be kept in view. Wheat, barley, oats, flax, many grain-Leguminosae, many fruit trees, are characterized by polyphyletic origin.

This circumstance complicates the picture of their spreading. The same fact must be taken into consideration when studying the genesis of domestic animals and of man.

It goes without saying, that artificial selection, the interference of man's will, have been able in separate cases to spoil the general scheme. Hornless, dominant cattle are chiefly propagated in the North of Russia, being but of rare occurrence in the South. Dominant awnless wheat is nowadays preferred by the whole cultured world. The population of Abyssinia, living in the vicinity of the towns, wants whitegrained wheat and white barley (the latter does not serve as fodder for cattle but is used for the preparation of beer and bread).

The occurrence of black cultivated oats in the North of Europe is evidently connected with the individual origin of this group. Ac- 
cording to our investigations cultivated oats are of very complex polyphyletic origin. Red-grained wheats better correspond in their physiological properties to the moist North and are preferred in cultivation to recessive white-grained races. Domestic animals and cultivated plants, being connected with man, reflect the will of the latter and the higher the culture of a given country, the more this will manifest itself.

These separate exceptions do not spoil the general aspect of the picture whose meaning is to reveal the essence of the evolution process of species in space and time.

The investigations of the last years have complicated our conception of dominance and recessiveness of the characters. The same, extremely equal, characters may be in different races and species dominant, as well as recessive. Thus, for instance, the winter and spring habit of life in plants (Vavilov, Kuznetzova, 1922), the colour of the glumes in cereals, the colour of the flowers, are not always equally dominant. The green cotyledons of the Leguminosae may be in different plants dominant, as well as recessive.

The hypothesis of the presence and absence of genes, devised by W. Bateson, was subjected to criticism. Henceforth, recessive mutations, recessive forms, cannot always be conceived of as the loss of genes. The phenomena of multiple allelomorphs make us alter our former ideas as to the nature of Mendelizing differences. Recessive mutations may be conceived of as the result of corresponding qualitative changes in the initial genes, not only as the result of the falling out of the factors for dominant characters.

These complications in our conceptions regarding the nature of recessive and dominant characters must be taken into consideration. But at the same time, experiment and observation reveal in the majority of cases a marked difference between dominants and recessives. Whether we consider the recessive forms as the loss of a gene - a scheme which in the majority of cases is still very convenient in describing phenomena (Bateson, 1926) - or regard them as a different qualitative constitution of the gene - it does not essentially alter our conception as to the geographical distribution of dominant and recessive forms within the limits of a Linnean species.

\section{§5. General characteristic OF THE} CENTRES CONTAINING AN ACCUMULATION OF GENES FROM AN UTILITARIAN POINT OF VIEW

The geographical focuses of the concentration of genes and the probable centres of their origin comprise by far not always the phenotypes necessary to man. The wheats and barleys of Abyssinia, though characterized by and extreme abundance of genes, are in themselves of no practical interest for the European plant breeder. An overwhelming majority of races in Abyssinia and Eritrea correspond in result of natural selection to the short equatorial day; the majority of races in mountainous East Africa are spring forms and poorly tillered.

The plant breeder must know how to choose among the diversity of chiefly dominant genes those which are able to serve his purpose. It is very probable that the most interesting combinations for European cultivation are the recessive ones, the recessive genes. It is the building material that is required by the plant breeder, but it lies with him to create necessary combinations. The geographical centres of diversity, the probable focuses of the origin of cultivated plants and domestic animals, are of practical value representing a rich stock of dominant and recessive genes from which the plant breeder must choose what is of interest 
to him, leaving the most frequent dominant forms which prevail in the native country due to free combination.

The concentration itself of an abundance of genes in the centres where the forms have originated, not always favours harmonious combinations in the sense of the plant breeder. This may be the reason of the poor agricultural value of the Asiatic and African varieties, of the low degree of culture shown by the peoples living in the ancient seats of agriculture. The cultivated type in the scheme, is the recessive type, as it is perfectly obvious in plant, animal, and man itself.

\section{§. CONCLUSION}

Thus, the author approaches from another side the idea put forth by his teacher, W. Bateson (1914), that the process of evolution must be regarded as a process of simplification, the unpacking of the tangle of primary genes.

The author determines the geographical process of evolution of a Linnean species as the dispersal of the accumulation of genes from the principal centres of the origin of forms, as the decrease of dominant genes from the centres towards the periphery, the separation of recessive combinations and the partly emancipation of genes (if the scheme of Bateson, who understands dominance and recessiveness as presence and absence of genes, by true ${ }^{3)}$ ).

From a general cultural-historical point of view this process was positive, having given rise to the great cultures of the North. Genetically they have, being recessive in the composition of their genes, brought under their control the potentially richer conglomerates of genes of the initial peoples living in the primary seats of human culture.

Such is the general inductive scheme of geographical regularities, to which we have been led by the direct study of geographical forms within the limits of Linnean species, and of their distribution over the earth. Much effort will be still required on the part of the investigator in order to trace on a great number of characters, the exact course taken by the process of geographical evolution. So far, the geneticist has left almost untouched a field that promises to reveal facts of first-rate importance for the understanding of the evolution of the separate species.

The Mediterranean, Steamer Crispi, April 22-d, 1927.

The on-line republication of this paper was supported by the Federal Program "Scientific and Research-Pedagogical Staff of Innovated Russia” (2009-1.1-141-063-021).

\section{REFERENCES}

Bateson W. 1914. Presidential address to the British Association // Nature. 93: 635-642.

Bateson W. 1926. Segregation // J. Genet. 16: 201235.

Flaksberger C.A. 1926. Liguleless durum wheats of the island Cyprus // Bull. Appl. Bot. Plant Breed. (Leningrad). 16(3): 201-233.

Vavilov N. 1926. Studies on the origin of cultivated plants // Bull. Appl. Bot. Plant Breed. (Leningrad). 16(2): 1-248.

Vavilov N., Kuznetzova E. 1922. On the genetic nature of winter and spring races in plants // Ann. Agr. Fac. Univ. Saratov. 1.

Suggested for republication by N.Sh. Bulatova, June 26, 2009.

Republished August 6, 2009

${ }^{3)}$ For our conception it is indifferent if even it is definitely refuted. 